Art, Illustration and Visual Culture

in Infant and Primary Education

\title{
El proyecto OEPE: un análisis de la singularidad de la educación patrimonial para conocer puntos fuertes, ausencias y retos en la construcción de identidades
}

Oepe España grupodeinvestigacionoepe@gmail.com Universidad de Valladolid, España

Reference

España, Oepe; (2012) "El proyecto OEPE: un análisis de la singularidad de la educación patrimonial para conocer puntos fuertes, ausencias y retos en la construcción de identidades", p. 93-97 . In: Barbosa, Helena; Quental, Joana [Eds]. Proceedings of the 2nd International Conference of Art, Illustration and Visual Culture in Infant and Primary Education. São Paulo: Blucher, 2015. ISSN 2318-695X, ISBN: 978-989-98185-0-7

DOI 10.5151/edupro-aivcipe-19

A través del Observatorio de Educación Patrimonial en España (OEPE)1 se pretende cubrir una línea ausente, tratando de evitar una posible y más que probable convergencia con proyectos de orden internacional en los que España no tiene presencia actualmente, a pesar de ser el segundo país con más bienes declarados patrimonio de la humanidad. En el seno del proyecto se ha generado una extensa base de datos en la que se recogen más de 1000 programas de educación formal, no formal e informal. Planteamos un recorrido en el que las experiencias significativas y las ausencias detectadas determinan la visión panorámica y colectiva de la educación artística y patrimonial en la actualidad. Exploramos un camino donde nos detendremos en ejemplos únicos que nos permiten conocer diversos y novedosos enfoques educativos, así como modos de abordar el patrimonio y lo que este significa, el establecimiento de conexiones, la construcción de la memoria, la definición de identidades y las relaciones entre bienes y personas, a nivel singular y plural, en todos los contextos educativos.

Palabras clave Educación patrimonial, educación artística, memoria e identidad, experiencias significativas.

Abstract

Through the Observatory of Patrimonial education in Spain (OEPE) is intended to cover a missing line, trying to avoid a possible and more than likely convergence with international projects in which Spain has no presence today, despite being the second country with more goods declared heritage of the world. Within the project there has been an extensive database which contains more than 1000 formal, non-formal and informal education programs. We propose a journey in which the significant experiences and detected absences determine panoramic and collective vision of artistic and heritage education today. We explore a path stopping at examples that allow us to meet diverse and innovative educational approaches, as well as ways of addressing the heritage and what this means, the establishment of connections, the construction of memory, the definition of identities and relations between goods and people, singular and plural, level in all educational contexts.

Keywords heritage education, artistic education, identity and memory, meaningful experiences

\section{Introducción}

El Observatorio de Educación Patrimonial en España (OEPE) es un proyecto de I+D+i nacional con el que se pretende cubrir una línea ausente en la educación patrimonial en España tratando de evitar una posible y más que probable convergencia con proyectos de orden internacional en los que España no tiene presencia. En el seno del proyecto se ha generado una extensa base de datos en la que se recogen más de 1000 programas de educación formal, no formal e informal. Este volumen de entradas nos ha permitido analizar y conocer el estado actual, así como 
2nd International Conference Art, Illustration and Visual Culture in Infant and Primary Education $2^{\circ}$ Congreso Internacional

Arte, llustración y Cultura Visual en Educación Infantil y Primaria esso Internacional

de Arte, llustração e Cultura Visual

na Educação Infantil e Primária

\section{El enfoque relacional: el patrimonio como relación entre bienes y personas}

profundizar en el conocimiento de programas educativos que se configuran como ejemplos de buenas prácticas en el trabajo desde y con la educación patrimonial.

Planteamos un recorrido en el que las experiencias significativas y las ausencias detectadas determinan la visión panorámica y colectiva de la educación artística y patrimonial en la actualidad. En esta profunda revisión nos detendremos en ejemplos únicos que nos permiten conocer diversos enfoques educativos y situaciones a explorar para trabajar el patrimonio y lo que este significa; el establecimiento de conexiones, la construcción de la memoria, la definición de identidades y relaciones entre bienes y personas en todos los contextos educativos.

El Patrimonio, en función del punto de vista desde el cual lo observemos, tiene múltiples significados. Para aproximarnos a una interpretación que se acerque y ajuste con coherencia a nuestros planteamientos es necesario conocerlo desde todas las perspectivas posibles, valorando todas las posibilidades de significación existentes. De esta forma podremos generar una definición propia con la certeza de estar basándonos en un conocimiento profundo de su naturaleza.

En la actualidad podemos afirmar que el patrimonio cultural ha experimentado cambios significativos iniciados en el último siglo, como la transición de un uso limitado al turismo para orientarse a un uso social más intensivo. En ese uso es importante la mediación entre los bienes y los individuos, precisamente porque se pasa de dar mayor importancia a los bienes patrimoniales para concedérsela a los individuos, y comienzan a aparecer formas de mediación que se ocupan de la diversidad de públicos posibles.

Desde el OEPE, Observatorio de Educación Patrimonial en España, apostamos por la educación patrimonial para garantizar la innovación en este campo, la valoración, respeto y conservación de nuestro patrimonio, así como para cambiar los modelos establecidos, ampliando y profundizar en el conocimiento de la realidad patrimonial.

Abordamos el concepto patrimonio en su vertiente cultural, formado por los bienes elaborados por el hombre que la historia ha legado y aquellos que se crean en el presente y que poseen un valor especial, en base a las cinco dimensiones que propone Fontal (2004): se presenta en un soporte material, inmaterial y espiritual; está sujeto a la atribución de valores; define y caracteriza a individuos, grupos y culturas (define identidades); caracteriza contextos y se transmite generacionalmente. En este sentido nos referimos al patrimonio como las relaciones que se establecen entre las personas y los objetos heredados, sumados a los que genera la cultura contemporánea, que intervienen en la creación de lazos identitarios y que se transmiten de generación en generación.

La educación patrimonial deberá ayudar al individuo a desarrollarse plenamente en todas sus potencialidades para generar un proceso consciente de apropiación e inserción en su medio social, así como en los procesos de conocimiento, comprensión, valoración, cuidado, disfrute y difusión de aquellos objetos materiales e inmateriales y aspectos intangibles heredados de su cultura. Finalmente, la educación patrimonial debe pretender la configuración de las identidades individual y social, así como la conservación y valoración de los bienes patrimoniales en la medida en que éstos son parte de nuestros referentes identitarios; cuidarlos y conservarlos es hacer lo propio con nosotros mismos como individuos y miembros de un grupo. Es decir, necesariamente se encarga de los procesos de "patrimonialización", de las relaciones identitarias entre bienes e individuos.

Qué puede ser patrimonio y qué puede adjetivarse como patrimonial dependerá de la mirada de la persona y de la cualidad que le otorgue. Fontal (2008)², plantea un ejemplo muy ilustrativo; no considerará el mismo tipo de bienes como patrimonio un historiador que un geógrafo, ni un sociólogo que un político. La diferencia es tal que, todo lo que cada uno a título individual considere como parte de su patrimonio se configura como tal al menos en el ámbito de su propia identidad. De esta forma podemos hablar de patrimonio individual y patrimonio colectivo. 
$2^{\text {nd }}$ International Conference Art, Illustration and Visual Culture in Infant and Primary Education
${ }^{\circ}$ Congreso Internacional

Arte, Ilustración y Cultura Visual en Educación Infantil y Primaria
Congresso Internacional

de Arte, llustração e Cultura Visual

na Educação Infantil e Primária

\section{Diversos "modos" de trabajar con el patrimonio desde la educación: estrategias}

Figura 1. Modelos de Didáctica del Patrimonio en base a la priorización de variables
No existe una única forma que, a modo de receta o solución, nos indique cómo debemos abordar el patrimonio educativamente, y tampoco sería deseable. Existen multiplicidad de planteamientos, enfoques educativos y estrategias que enriquecen las prácticas de educación patrimonial, aportando diversas perspectivas que amplían sus posibilidades. Hemos configurado una reordenación propia de los modelos que inferimos de las prácticas recogidas, organizados en orden creciente de una menor a una mayor complejidad de interrelación entre las variables fundamentales de los procesos de enseñanza aprendizaje: profesor/docente/educador, educando/discente/destinatario, contenido y contexto.

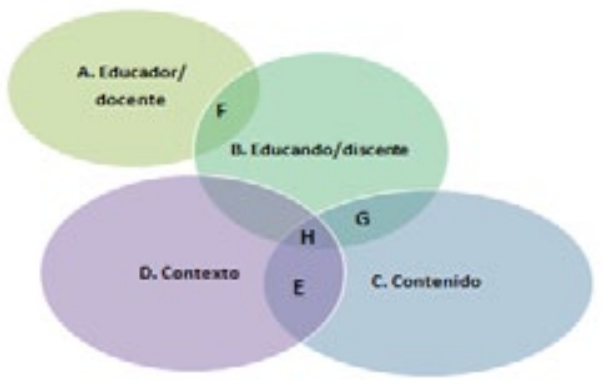

Definimos un total de ocho modelos educativos, empezando por el de menor complejidad, donde el acento recae en el profesor, el docente que educa y se presenta como experto en la materia. La principal estrategia didáctica es la transmisión de los contenidos de forma vertical. En este enfoque nos referimos a cursos, seminarios, congresos, como por ejemplo el I Congreso Internacional Patrimonio Cultural Inmaterial de la Humanidad en España, organizado por la Cátedra Misteri d’Elx Universitas Miguel Hernández, eventos que se caracterizan por ser referentes, reuniendo expertos y profesionales en la materia.

En segundo lugar situamos aquellos planteamientos que se centran en el sujeto que aprende. El profesor actuará como guía, facilitando el proceso y tomando en cuenta los conocimientos previos del alumno para que tenga lugar un aprendizaje significativo. Podría encajar en este modelo el programa Aprendiendo con arte, patrimonio y sociedad, de la Asociación Bitartean, donde diseñan talleres prácticos con el objetivo de, partiendo de los conocimientos previos de los alumnos, llegar a un conocimiento más general, sensibilizando acerca del patrimonio.

Cuando los contenidos se centran en aspectos conceptuales y la metodología se define en base a esto estamos hablando de un modelo educativo cuyo interés se focaliza en el contenido a enseñar. Avanzando en nuestra clasificación, dependiendo de cuáles sean los intereses de referencia, podemos hablar de otro enfoque caracterizado por el contexto. En este caso se da importancia al lugar donde acontecen los procesos de enseñanza aprendizaje, y los factores protagonistas de éstos, como los intereses de los destinatarios, las necesidades, recursos, etc. Como ejemplo ilustrativo de este enfoque destacan todas aquellas iniciativas que se centran en un contexto determinado, a través de metodologías participativas, como los talleres de arqueología que organiza el Gabinete pedagógico de bellas artes de Málaga, donde los alumnos observan y realizan el proceso de trabajo que se desarrolla entre la excavación y la exhibición de los restos materiales en un museo.

En otros casos la variable más importante son las relaciones entre contexto y contenido. Proyectos didácticos cuya estrategia principal es la práctica en vivo, en el lugar donde los contenidos tienen mayor significatividad. Por ejemplo Agua de mar, de la fundación Josep Plá, donde se asocian lecturas, paisaje y experiencias.

Atendiendo a las relaciones posibles entre docente y educando, nos acercamos al modelo descrito por Fontal (2003) en su libro "La educación Patrimonial", el modelo mediacionista, para mediar entre sociedad y patrimonio, estableciéndose el educador como puente entre los nuevos contenidos y los educandos que van a aprender. 
$2^{\text {nd }}$ International Conference Art, Illustration and Visual Culture in Infant and Primary Education $2^{\circ}$ Congreso Internacional

Arte, llustración y Cultura Visual en Educación Infantil y Primaria de Arte, llustracão e Cultura Visual

na Educação Infantil e Primária
Acercándonos a los modelos más complejos según nuestra clasificación, encontramos propuestas educativas donde la variable principal son las relaciones que se establecen entre el destinatario de la enseñanza y los nuevos contenidos, aproximándonos al aprendizaje significativo y la construcción a partir de los conocimientos previos.

Por último, y como modo más complejo de educar en el patrimonio según la clasificación que hemos definido, el modelo basado en las relaciones entre discente, contenido y contexto. Las estrategias de enseñanza se adaptan en función de los intereses de los alumnos, los contenidos que se quieren enseñar y su relación dentro del contexto donde tienen lugar los procesos de enseñanza aprendizaje.

\section{Algunos ejemplos significativos de educación patrimonial en España}

Figura 2. Imágenes compartidas por los usuarios. Programa It's our Heritage. Fuente: ICCROM y Facebook.
Cuando queremos trabajar la educación patrimonial enfocando nuestro interés hacia la sensibilización, y ésta hacia la comprensión y el respeto, es necesario tener en cuenta que existen tantas formas de comprenderlo y sentirlo como personas hay en el mundo. Esto nos lleva a tomar conciencia de la riqueza del trabajo con y para las personas profundizando en la esencia del hombre como ser individual y social.

En este sentido destaca el proyecto del ICCROM 3 , un proyecto de carácter internacional en el que España tiene presencia, It's our Heritage, una iniciativa interactiva a través de las redes sociales, donde se crea un escenario para compartir el patrimonio local de forma individual, aportando puntos de vista únicos y personales. Desde la famosa red social Facebook, generan un álbum fotográfico que surge a partir de las aportaciones personales de los usuarios, quienes cuelgan las imágenes de su patrimonio más próximo y/o personal, dando lugar a un muestrario diverso de patrimonios posibles, puntos de vista e interpretaciones que se comparten de forma instantánea con usuarios de todo el mundo.

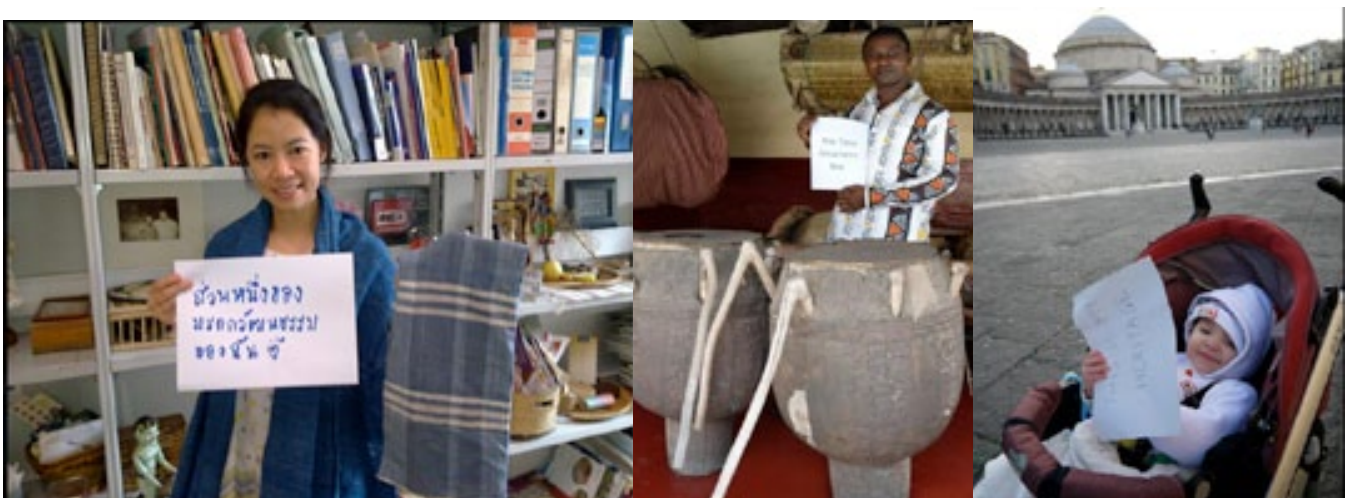

Aproximándonos al contexto de España, el grupo Ciudades patrimonio de la Humanidad de España acerca el patrimonio a los más jóvenes por medio de la lectura. A través del proyecto Ciudades de Cuento aproximan las historias y riquezas del patrimonio de cada una de las ciudades declaradas patrimonio de la humanidad en España, ofreciendo la oportunidad de que los niños conozcan mejor el patrimonio que heredan.

Dando un paso más en ese recorrido que hemos iniciado, es interesante detenernos en el Concurso "Los nueve secretos", una iniciativa de la Fundación de Patrimonio Histórico de Castilla y León que está teniendo una gran acogida en los últimos años. Se convoca mediante este concurso a los centros escolares de Castilla y León a participar elaborando sus propuestas, despertando el interés por un bien patrimonial de su entorno. A través de la investigación y la propuesta de futuro para el bien elegido, los alumnos optan a premios diversos: viajes culturales, publicaciones, y, lo más importante, la inclusión del bien patrimonial elegido en los planes de restauración de la fundación. A raíz de este concurso, de convocatoria anual, se está generando un extenso archivo de propuestas presentadas, que constituyen un amplio catálogo de formas de abordar la educación patrimonial. 
$2^{\text {nd }}$ International Conference Art, Illustration and Visual Culture in Infant and Primary Education $2^{\circ}$ Congresso Internaciona

de Arte, Ilustração e Cultura Visual

na Educação Infantil e Primária
Figura 3. Miembros del equipo OEPE catalogando algunos de los proyectos presentados. Fuente: propia

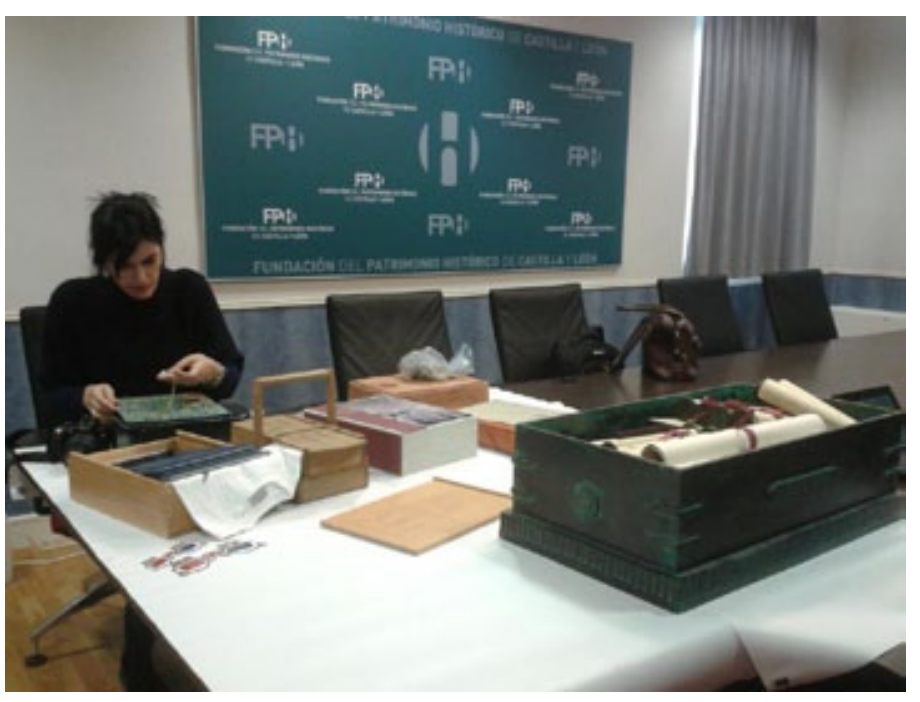

Los avances conseguidos en la base de datos del Observatorio están haciendo posible profundizar en el conocimiento de lo modos, metodologías, estrategias, enfoques y perspectivas diversas desde las cuales podemos divisar la educación patrimonial, reflexionar en torno a sus prácticas, detectar referentes, puntos débiles y puntos fuertes en este ámbito.

Este observatorio va más allá, generando un portal que será consultable para todos los usuarios e investigadores que lo requieran, abriendo las puertas al conocimiento de tan amplia diversidad de propuestas de educación patrimonial y facilitando la relación y la generación de redes entre profesionales y personas interesadas en involucrarse en una educación de nuestro patrimonio, nuestra identidad, recuerdos y memoria, de calidad.

\section{Referencias bibliográficas}

Fontal Merillas, O. (2003). La Educación Patrimonial. Teoría y práctica en el aula, el museo e internet. Gijón: Trea.

Fontal Merillas, O. (2004). Museos de arte y TICs: usos, tipologías, ejemplos y derivaciones. En Vera Muñoz, M.I. y Pérez, D. (Coord.), Formación de la ciudadanía: las TICs y los nuevos problemas. Alicante: Asociación Universitaria de Profesores de Didáctica de las Ciencias Sociales.

Fontal Merillas, O. (2008). La importancia de la dimensión humana en la didáctica del patrimonio. En Rusillo, M., La comunicación global del patrimonio cultural (pp. 79-110). Gijón: Trea.

Ciudades Patrimonio de la Humanidad de España [Consult. 16/03/2012]. Disponible en <http://www. ciudadespatrimonio.org>

Fundación de Patrimonio Histórico de Castilla y León [Consult. 18/03/2012]. Disponible en < http://www. fundacionpatrimoniocyl.es/>

It's our heritage, ICCROM [Consult. 18/03/2012] Fotografía. Disponible en < http://www.iccrom.org/eng/ news_en/2012_en/various_en/o2_15itsourheritage_en.shtml> 